A.J. Morales ${ }^{1}$, I.M. Lasky ${ }^{1}$, C.A. Engelmann ${ }^{1}$, J. Reyes ${ }^{1}$, K.A. Ahmed ${ }^{1}$, I. Boxx ${ }^{2}$. "The Characteristics of Flame Stability at High Turbulence Conditions in a Bluff-Body Stabilized Combustor", AIAA Scitech 2019 Forum, (AIAA 20191734).

${ }^{1}$ University of Central Florida, Orlando, Florida.

${ }^{2}$ Institute of Combustion Technology, German Aerospace Center. Stuttgart.

The AIAA version of the paper is accessible at https://doi.org/10.2514/6.2019-1734

On the AIAA web page https://arc.aiaa.org/doi/abs/10.2514/6.2019-1734

the interested reader can find other material published by AIAA 


\title{
The Characteristics of Flame Stability at High Turbulence Conditions in a Bluff-Body Stabilized Combustor
}

\author{
Anthony J. Morales*, Ian M. Lasky ${ }^{\dagger}$, Christian A. Engelmann ${ }^{\ddagger}$, Jonathan Reyes ${ }^{\S}$, and Kareem A. Ahmed ${ }^{\llbracket}$ \\ University of Central Florida, Orlando, Florida, 32816 \\ Isaac Boxx"l \\ Institute of Combustion Technology, Cologne, Germany
}

\begin{abstract}
Flame extinction dynamics are investigated for highly turbulent premixed bluff-body stabilized flames within a blow-down combustion facility. Blowout is induced through the rapid reduction of fuel flow into the reactant mixture. A novel turbulence generator is designed to modulate inflow turbulence levels. The turbulence generator implements both jet impingement and grid-based methods to vary turbulence across a wide range of intensities, including the thin reaction regime and pushing into the broken reaction regime. The effects of the induced turbulence on the extinction event is captured through simultaneous high-speed time-resolved particle imaging velocimetry (PIV) and $\mathrm{C}_{2}^{*}-\mathrm{CH}^{*}$ species measurement techniques. Flame structure, flow field, and strain rate analyses are employed to detail the driving mechanisms of blowout under various turbulent inflow conditions. It is demonstrated that with increased turbulence intensities, the strain rate along the flame boundary is attenuated, resulting in longer of extinction time-scales and improved flame stability.
\end{abstract}

\section{Nomenclature}

$H \quad=$ bluff-body height

$\kappa=$ strain rate along the flame

$L_{f} \quad=$ laminar flame thickness

$n_{x}=$ horizontal normal component along the flame

$n_{y}=$ vertical normal component along the flame

$\phi \quad=$ equivalence ratio

$S_{L} \quad=$ laminar flame speed

$S_{T} \quad=$ turbulent flame speed

$U_{0} \quad=$ test section inflow velocity

$U_{\text {lip }} \quad=$ bluff-body lip velocity

$u, v=$ stream-wise and cross-stream velocity components

$u^{\prime}, v^{\prime}=$ root mean square stream-wise and cross-stream turbulent velocity fluctuations

$\bar{u} \quad=$ temporal mean stream-wise velocity

$v \quad=$ kinematic viscosity of air

$\omega \quad=$ span-wise vorticity

$x \quad=$ stream-wise direction

$y=$ cross-stream direction

\footnotetext{
*Graduate Research Assistant, Mechanical and Aerospace Engineering, University of Central Florida, Bldg. 154, Rm. 109, AIAA student member

${ }^{\dagger}$ Undergraduate Researcher, Mechanical and Aerospace Engineering, University of Central Florida, Bldg. 154, Rm. 109, AIAA Student Member

${ }^{\ddagger}$ Graduate Teaching Assistant, Mechanical and Aerospace Engineering, University of Central Florida, Bldg. 154, Rm. 109, AIAA Student Member

${ }^{\S}$ Graduate Research Assistant, Mechanical and Aerospace Engineering, University of Central Florida, Bldg. 154, Rm. 109 and AIAA Student Member

IIAssistant Professor, Mechanical and Aerospace Engineering, University of Central Florida, Bldg. 154, Rm. 109. and AIAA Member

"Senior Scientist, Deutsches Zentrum für Luft- und Raumfahrt (DLR)
} 


\section{Introduction}

M ODERN lean combustion technologies are fraught with flame extinction events that limit propulsion and energy generation [1, 2]. Improvement of propulsion and energy conversion efficiencies and the reduction of harmful emissions is a critical issue for combustion systems. Lean premixed turbulent conditions significantly reduce thermal losses, curtail combustion emissions, and improve efficiency [3]. However, current combustion engines operating at lean conditions must also function within highly turbulent regimes that impart hydrodynamic disturbances upon the system. These disturbances can impede optimal engine performance and reliability, potentially resulting in lean flame blowout [4, 5]. It is therefore paramount to understand the hydrodynamic effects of turbulence on bluff-body stabilized flames to aid in the improvement of future combustion technologies.

A bluff-body can be used to induce turbulent mixing of inflow reactants and combustion products which generates advantageous conditions for stable combustion [6]. Flow separation at the trailing edge of the bluff-body produces a recirculation zone that provides the necessary conditions for turbulent mixing [7- -9 ]. Inflow reactants are first ignited within shear layers of high vorticity concentrations bounding the recirculation zone. The reactants burn, become entrained within the recirculation zone, and cycle back to the upstream shear layers to ignite fresh reactants [7]. This interaction between cold inflow reactants and hot combustion products provides the basis for flame stabilization.

During combustion, turbulence effects drastically influence flame stability mechanisms through hydrodynamic modulation [10-13]. Borghi demonstrated that increased turbulence intensities correspond to greater flame wrinkling [14] thereby increasing the surface area and in turn the turbulent flame speed [15]. Modified flame speeds directly influence flow dilatation and baroclinic flame-generated vorticity magnitudes leading to changes in flame structure and stability [16]. In addition to bulk flow rates and turbulence effects, flame stability is highly dependent upon the reacting equivalence ratio [17, 18]. Decremented equivalence ratios result in reduced flame speeds thereby exposing the flame brush to strong vorticity concentrations in the bluff-body shear layers [19--21]. The shear layer vorticity elements impart strain upon the flame; the elevated strain rates stretch the flame beyond the limits a coherent flame structure can be maintained, inducing localized flame holes [5, 16, 19]. The flame holes allow for additional reactant entrainment into the recirculation region, further altering the local equivalence ratio, enabling for the possibility of global blowout.

Flame blowout occurs when the flame ceases to exist within the recirculation zone and results in a decrease of performance and efficiency [5, 19, 20, 22]. Within the recirculation zone, variabilities within the flow field can increase flame volatility and therefore give way for the development of a sinuous structure reminiscent of Bénard-von Kármán (BVK) shedding [23, 24]. The reduction of equivalence ratio makes the sinuous structure more pronounced, exposing the flame edge to turbulent flow field effects thereby promoting higher localized strain rates along the flame [25]. Therefore, it is evident that turbulent flow modulations can impart instabilities upon the flame and directly affect the stability of lean combustion.

Building upon these works, the present research seeks to expand upon the consequences of turbulent inflow conditions on a bluff-body stabilized flame during an extinction event - specifically, the effect of increased turbulence on flame stability and the resulting strain rate along the flame front. Through use of a novel turbulence generator, the results of various inflow turbulence levels on flame extinction are investigated. The findings of this investigation will contribute to the enhanced understanding of the flame blowout mechanisms. Furthermore, the influences of increased turbulence levels upon such mechanisms will catalyze the understanding of flame stability within highly turbulent combustion technologies.

\section{Experimental Setup and Procedure}

Bluff-body flame extinction is investigated in a blow-down combustion facility. The primary components of the combustion facility include a flow conditioning plenum, a turbulence generator, and an optically accessible test section as depicted within Fig. 11. High pressure air is ducted into the flow conditioning plenum and adjusted with the combination of a pneumatic JFlow valve, a Venturi flow meter, and a Dwyer pressure transducer. The bulk flow rate is controlled through the use of a feedback loop within a LabVIEW software package. Gaseous propane is introduced sufficiently upstream of the plenum to achieve a fully premixed reactant mixture. The premixed propane-air flow enters the conditioning plenum through a conical diffuser and expands into the rectangular plenum. The plenum is fitted with four wire mesh screens to facilitate flow conditioning; each screen is located at a different location along the plenum length. Immediately following the plenum is a fifth order polynomial nozzle reducer that exhausts into the turbulence generator and test section. 
(A)

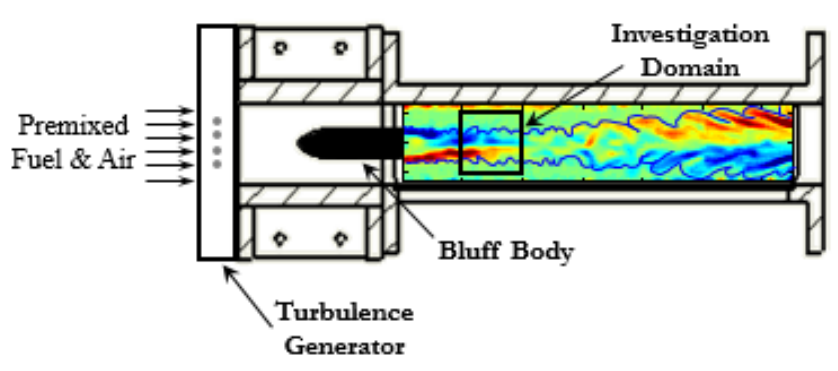

(B)

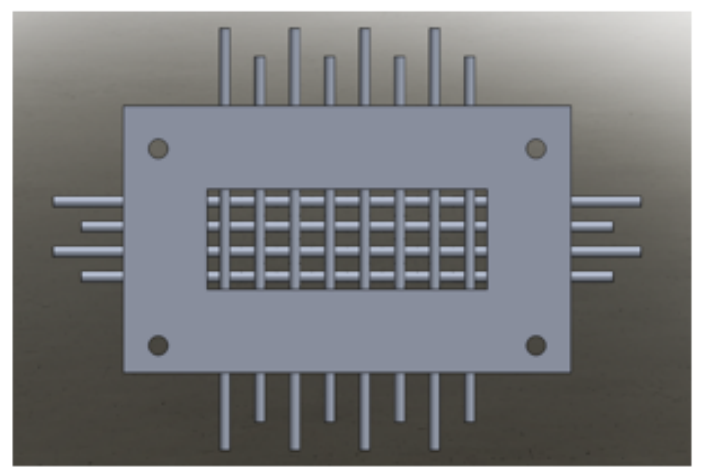

Fig. 1 Components of turbulent combustion facility. (A) Test section and (B) Turbulence generator grid.

The turbulence generator is a novel impinging jet grid-based turbulence generator capable of generating a wide array of turbulence levels; the design is shown in Fig. 11p. This turbulence generator is based upon designs used within related works [13, 26-31]. The design implements a combination of grid-based and fluidic jet impingement methods, allowing for a wide range of turbulent conditions to be achieved. The grid is comprised of eight vertical and four horizontal aluminum tubes forming a square mesh array. The blockage ratio (also known as grid solidity) of the square mesh is $61.9 \%$ of the total test section area.

The aluminum tubes that comprise the turbulent mesh grid are hollow and fitted with hoses to allow for fluidic jet impingement perpendicular to the bulk flow. Along the length each tube, 1/32 inch holes are spaced at 1/2 inch intervals and are small enough to ensure that the impinging jet flow is choked at the outlet. Choking the premixed propane-air flow creates underexpanded jets that impinge upon one another, creating small-scale sonic Mach discs that oscillate at high frequencies. The rapid oscillations of these Mach disks generate high turbulence intensities within the flow field. The ability to modulate the flow rate of the impingement jets allow for dynamic tailoring of turbulence levels.

Following the turbulence generator is the bluff-body which is vertically centered within the test section. The length and height of the bluff-body are $64 \mathrm{~mm}$ and $16 \mathrm{~mm}$, respectively, and the width spans the full width of the test section. For optical measurements to be obtained, the test section is viewable through fused quartz windows. All walls are fitted with these windows except for the top wall which is painted black to minimize light scattering within the test section.

Simultaneous PIV and $\mathrm{C}_{2}^{*}$ - $\mathrm{CH}^{*}$ imaging techniques are implemented to capture, and subsequently analyze, the extinction event. $15 \mu \mathrm{m}$ aluminum oxide particles are seeded upstream of the conditioning plenum and are used for PIV measurements. A dual-head $532 \mathrm{~nm} \mathrm{Nd:Yag} \mathrm{laser} \mathrm{is} \mathrm{pulsed} \mathrm{at} 20 \mathrm{kHz}$ to illuminate the seed particles. The laser is synchronized with a Photron SA-1 high-speed camera allowing for the temporal evolution of the extinction event to be captured. A second Photron SA-1 was implemented to capture the species measurement of $\mathrm{C}_{2}$ and $\mathrm{CH}^{*}$. As the equivalence ratio varies, the radiation emitted from each species also varies. Correlating the change of each allows for the calculation of local equivalence ratio information [32, 33].

A reactant mixture at an equivalence ratio of $\phi=0.7$ enters the test section. Flame ignition is achieved through use of a spark wire that protrudes from the side of the bluff-body. Once stable, flame extinction is induced by rapidly diminishing the propane fuel into the reactant mixture. During this, PIV and $\mathrm{C}_{2}^{*}-\mathrm{CH}^{*}$ images are captured to show the entire evolution of the extinction event from stable to blowout. Once captured, the flame boundary is determined using the seed particle density jump of the PIV Mie scatter images. At this flame edge, flow properties are extracted, including: stream-wise and cross-stream velocities, span-wise vorticity, and the local strain rate along the flame.

\section{Results}

Presented within this work are the effects of tailoring the turbulent inflow conditions upon extinction phenomenon of lean bluff-body stabilized flames. Three turbulence conditions are analyzed as outlined by table 1 .

The instantaneous flame structure, vorticity field, and localized strain rates along the flame are shown in Fig. 2 The local strain rate along the flame is calculated using equation 1 . Here, $n_{x}$ and $n_{y}$ are the local horizontal and vertical normal components of the flame.

$$
\kappa=-n_{x} n_{y}\left(\frac{\partial v}{\partial x}+\frac{\partial u}{\partial y}\right)+\left(1-n_{x}^{2}\right) \frac{\partial u}{\partial x}+\left(1-n_{y}^{2}\right) \frac{\partial v}{\partial y}
$$


Table 1 Experimental Test Conditions

\begin{tabular}{|c|c|c|c|c|c|}
\hline Test Case & $\begin{array}{c}\text { Turbulence } \\
\text { Level }\end{array}$ & $\begin{array}{c}\text { Operational } \\
\text { Mode }\end{array}$ & $\phi$ & $R e=\bar{u} H / v$ & $\sqrt{u^{\prime 2}+v^{\prime 2}}$ \\
\hline 1 & Low & No Grid & $0.7 \rightarrow 0$ & 17,600 & 2.4 \\
\hline 2 & Mid & Static Grid & $0.7 \rightarrow 0$ & 17,600 & 6.7 \\
\hline 3 & High & $\begin{array}{c}\text { Impinging Jet } \\
\text { Grid }\end{array}$ & $0.7 \rightarrow 0$ & 21,600 & 15.0 \\
\hline
\end{tabular}
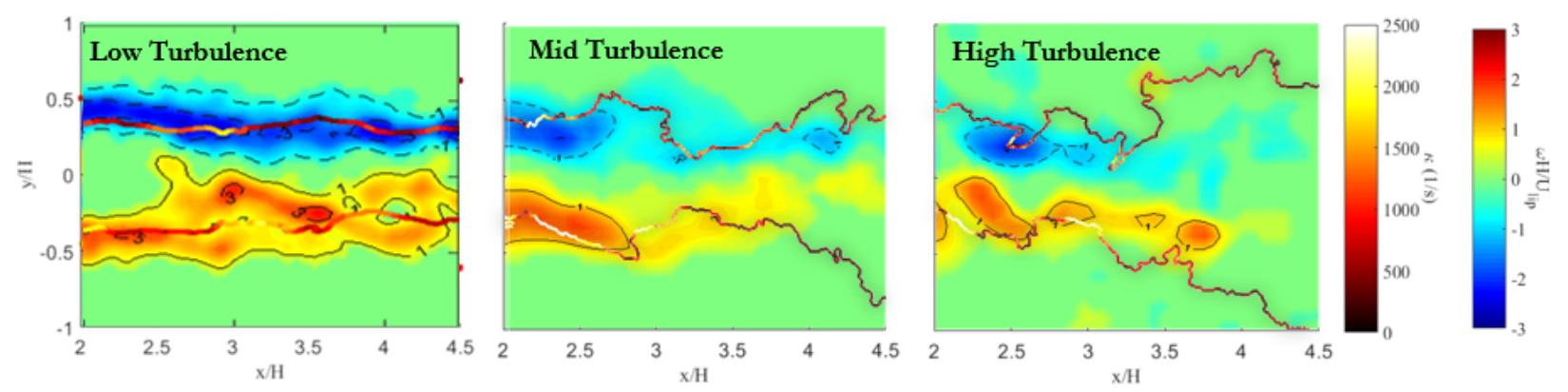

Fig. 2 Instantaneous flame structure, span-wise vorticity, and local strain rates for the three turbulence conditions. Snapshots are acquired halfway through the temporal extinction process.

As the induced freestream turbulence level increases, the flame structure increases in surface area and is comprised of more small-scaled wrinkles. The increased surface area of the flame promotes a faster turbulent flame speed; this is visualized by the flame topology within the high turbulence condition of Fig. 2 which experiences the widest flame brush of the three turbulence conditions. The increased burning flame velocity also influences the fluid mechanics within the immediate bluff body wake region where flame stabilization occurs. Increased freestream turbulence intensities will reduce the length of the of the bluff body recirculation zone and the length of the high magnitude shear layer vorticity region [34]. Within Fig. 2, it is evident that the low turbulence regime experiences the largest vorticity magnitudes; this strong vorticity is a result of the flow separation along the trailing edge of the bluff body. As the turbulence level increases, the vorticity magnitudes decrease within the investigation domain, and eventually break down into local discretized regions of high vorticity. The altered fluid mechanics will influence the overall structural stability of the flame; this is evident by the differences in the local strain rate magnitudes experienced by the flame. For the low turbulent flame, high strain rates are experienced along the lower boundary of the flame between $2 \leq x / H \leq 2.5$. As the turbulence level increases, the spatial regions of high strain rate magnitudes decrease and a minimal for the high turbulence regime. This implies that increased turbulence within the flow field will improve the overall stability of the flame.

Within Fig. 2 it is noteworthy that the spatial locations of high strain rate magnitudes occur when the flame boundary intersects with a region of high-magnitude vorticity. This is consistent with previous studies that hypothesize that high strain rates result from decreased turbulent flame speeds as the equivalence ratio reduces [16, 20, 22]. Reduced turbulent flame speeds push the flame boundary into regions of high vorticity, where local extinctions will occur and the recirculation zone will fail to ignite the shear layers. Therefore, it is important to understand how the flame-vorticity interaction dynamics will be effected by altering the freestream turbulence conditions.

The effect of the freestream turbulence levels on the flame-vorticity interaction are quantified within Fig. 3. Here, the vorticity within the shear layer and the vorticity experienced by the flame are compared for the three turbulence conditions. The shear layer vorticity is larger during stable burning for all turbulence conditions; the only exception is the slight overlap between the shear layer and flame vorticity magnitudes between $3.5 \leq x / H \leq 4.5$ for the high turbulence condition. This is again due to the shortened recirculation zone length for increased freestream turbulence levels. The reduced recirculation zone length allows for the span-wise vorticity to flip direction due to the production of baroclinic torque in the opposing direction. As the flame temporally approaches blow out, the shear layer vorticity magnitudes as well as the vorticity experienced by the flame both increase in magnitude and are seen to overlap near blowout. This indicates that the flame boundary will collimate and interact with the shear layer at reduced equivalence ratios, driving high strain rates along the boundary of the flame. 

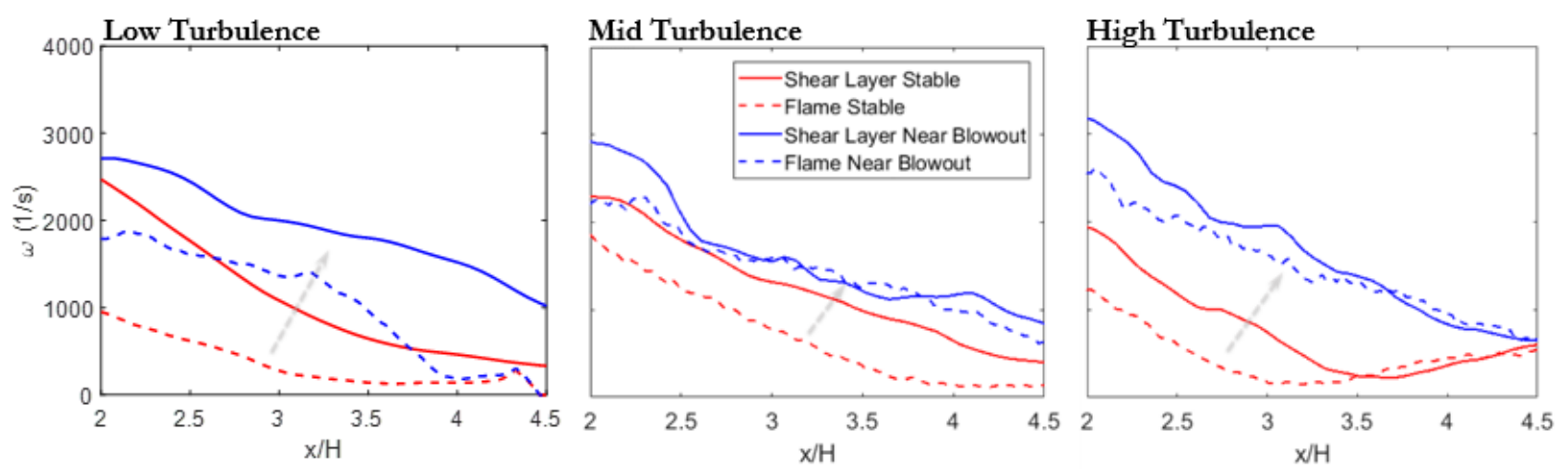

Fig. 3 Vorticity magnitudes experienced by the flame and within the shear layer for various freestream turbulence conditions.

To further investigate the influence of freestream turbulence on the strain rate evolution along the boundary of the flame, spatiotemporal strain rate profiles are provided within Fig. 4. The effects of the increased turbulence are best visualized by the strain contours within the later time segments. For the low turbulence regime, high strain-rate magnitudes are experienced along all portions of the flame between $2 \leq x / H \leq 4.5$. There are also multiple points where the local strain rate magnitude exceeds the maximum allowable strain rate tolerance $(\approx 1300(1 / s)$ for $\phi=0.7)$. As the turbulence level increases to the mid-turbulence regime, there are lower strain-rate magnitudes within the spatial regions of $3.5 \leq x / H \leq 4.5$. This is an effect of the reduced shear layer and recirculation zone length behind the bluff body. This trend is further exaggerated by the high turbulence burning regime, where there are larger regions of low strain within both the earlier and later stages of flame extinction. This demonstrates that higher freestream turbulence intensities reduce the spatial and temporal growth of the strain rate along the flame. An attenuated strain rate growth along the flame will promote flame stability, inhibit localized extinctions, and ultimately increase the total time duration of global flame blowout.
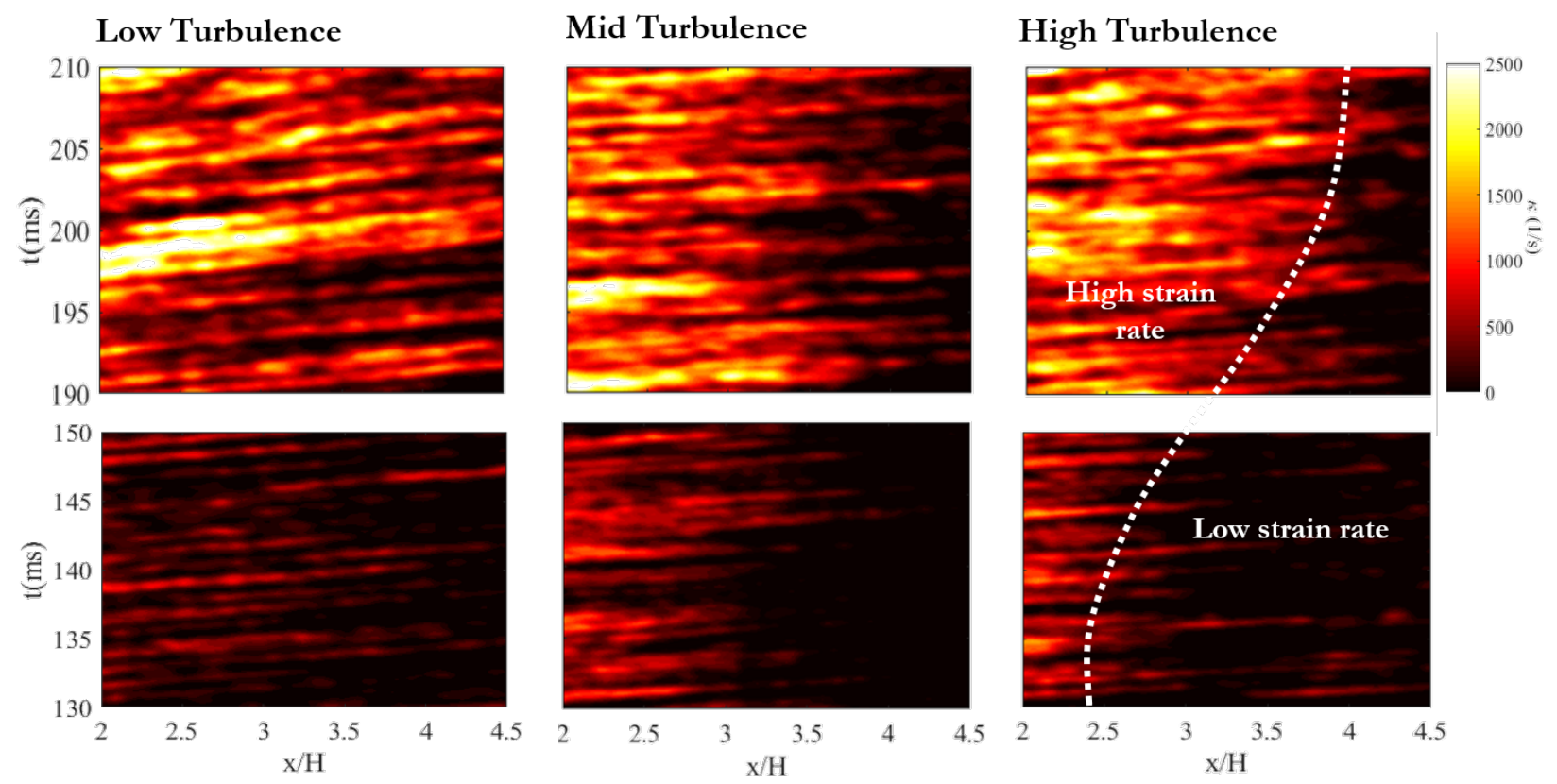

Fig. 4 Spatial and temproal strain rate evolution along the lower flame boundary for multiple freestream turbulence conditions. 


\section{Conclusion}

Bluff body flame extinction has been investigated for various freestream turbulence conditions. A dynamic turbulence generator was utilized to modulate turbulence levels with a combined static grid and fluidic jet impingement design to achieve a range of turbulence conditions. As the freestream turbulence levels were increased, the recirculation zone length was decreased while the flame spanned farther away from the bluff body centerline. This effectively hinders the interaction between the shear layer and flame and delays the manifestation of high strain rate magnitudes along the flame boundary. This indicates that the increased freestream turbulence aids in the stability of the flame by attenuating the fluidic mechanisms that cause localized extinction events.

\section{Acknowledgments}

The work is sponsored by the Air Force Office of Scientific Research (FA9550-16-1-0403, Program Manager: Dr. Chiping Li). This material is based upon work supported by the Air Force Office of Scientific Research under award number FA9550-16-1-0403.

\section{References}

[1] Ebrahimi, H., "Overview of gas turbine augmentor design, operation, and combustion oscillation," 42nd AIAA/ASME/SAE/ASEE Joint Propulsion Conference \& Exhibit, 2006, p. 4916.

[2] Lovett, J., Brogan, T., Philippona, D., Kiel, B., and Thompson, T., "Development needs for advanced afterburner designs," 40th AIAA/ASME/SAE/ASEE Joint Propulsion Conference and Exhibit, 2004, p. 4192.

[3] Dunn-Rankin, D., Lean combustion: technology and control, Academic Press, 2011.

[4] Candel, S., "Combustion dynamics and control: Progress and challenges," Proceedings of the combustion institute, Vol. 29, No. 1, 2002, pp. 1-28.

[5] Nair, S., and Lieuwen, T. C., "Near-blowoff dynamics of a bluff-body stabilized flame," Journal of Propulsion and power, Vol. 23, No. 2, 2007, pp. 421-427.

[6] Peters, N., Turbulent combustion, Cambridge university press, 2000.

[7] Zukoski, E. E., and Marble, F. E., "Experiments concerning the mechanism of flame blowoff from bluff bodies," 1983.

[8] Longwell, J. P., Frost, E. E., and Weiss, M. A., "Flame stability in bluff body recirculation zones," Industrial \& Engineering Chemistry, Vol. 45, No. 8, 1953, pp. 1629-1633.

[9] Roshko, A., "On the wake and drag of bluff bodies," Journal of the aeronautical sciences, Vol. 22, No. 2, 1955, pp. $124-132$.

[10] Pan, J., Vangsness, M., and Ballal, D., "Aerodynamics of bluff body stabilized confined turbulent premixed flames," ASME 1991 International Gas Turbine and Aeroengine Congress and Exposition, American Society of Mechanical Engineers, 1991, pp. V003T06A019-V003T06A019.

[11] Rizk, N., and Lefebvre, A. H., "Internal flow characteristics of simplex swirl atomizers," Journal of Propulsion and Power, Vol. 1, No. 3, 1985, pp. 193-199.

[12] Fujii, S., and Eguchi, K., "A comparison of cold and reacting flows around a bluff-body flame stabilizer," Journal of Fluids Engineering, Vol. 103, No. 2, 1981, pp. 328-334.

[13] Geikie, M. K., Morales, A. J., Engelmann, C., and Ahmed, K., "Turbulence-Flame Interaction in the Broken Reaction Regime," 2018 AIAA Aerospace Sciences Meeting, 2018, p. 0162.

[14] Borghi, R., “Turbulent combustion modelling,” Progress in energy and combustion science, Vol. 14, No. 4, 1988 , pp. $245-292$.

[15] Damköhler, G., "The effect of turbulence on the flame velocity in gas mixtures," 1947.

[16] Shanbhogue, S. J., Husain, S., and Lieuwen, T., "Lean blowoff of bluff body stabilized flames: Scaling and dynamics," Progress in Energy and Combustion Science, Vol. 35, No. 1, 2009, pp. 98-120.

[17] Ozawa, R., "Survey of basic data on flame stabilization and propagation for high speed combustion systems," The Marquart Co., TR AFAPL-TR-70-81, 1971. 
[18] Herbert, M., "Aerodynamic influences on flame stability," Progress in Combustion Science and Technology, Elsevier, 1960, pp. 61-109.

[19] Chaudhuri, S., Kostka, S., Renfro, M. W., and Cetegen, B. M., "Blowoff dynamics of bluff body stabilized turbulent premixed flames," Combustion and flame, Vol. 157, No. 4, 2010, pp. 790-802.

[20] Tuttle, S. G., Chaudhuri, S., Kopp-Vaughan, K. M., Jensen, T. R., Cetegen, B. M., Renfro, M. W., and Cohen, J. M., "Lean blowoff behavior of asymmetrically-fueled bluff body-stabilized flames," Combustion and flame, Vol. 160, No. 9, 2013, pp. 1677-1692.

[21] Geikie, M. K., and Ahmed, K. A., "Lagrangian mechanisms of flame extinction for lean turbulent premixed flames," Fuel, Vol. 194, 2017, pp. 239-256.

[22] Lieuwen, T., Shanbhogue, S., Khosla, S., and Smith, C., "Dynamics of bluff body flames near blowoff," 45th AIAA Aerospace Sciences Meeting and Exhibit, 2007, p. 169.

[23] Erickson, R., and Soteriou, M., "The influence of reactant temperature on the dynamics of bluff body stabilized premixed flames," Combustion and Flame, Vol. 158, No. 12, 2011, pp. 2441-2457.

[24] Kiel, B., Garwick, K., Lynch, A., Gord, J., and Meyer, T., "Non-reacting and combusting flow investigation of bluff bodies in cross flow," 42nd AIAA/ASME/SAE/ASEE Joint Propulsion Conference \& Exhibit, 2006, p. 5234.

[25] Hamlington, P. E., Poludnenko, A. Y., and Oran, E. S., "Interactions between turbulence and flames in premixed reacting flows," Physics of Fluids, Vol. 23, No. 12, 2011, p. 125111.

[26] Gad-el Hak, M., and Corrsin, S., "Measurements of the nearly isotropic turbulence behind a uniform jet grid," Journal of Fluid Mechanics, Vol. 62, No. 1, 1974, pp. 115-143.

[27] Hideharu, M., "Realization of a large-scale turbulence field in a small wind tunnel," Fluid Dynamics Research, Vol. 8, No. 1-4, 1991, p. 53.

[28] Slais, T. A., Ochs, B. A., Scarborough, D. E., Menon, S., Grady, N. R., and Pitz, R. W., "An experimental study of homogeneous anisotropic turbulence in channel flow," 53rd AIAA Aerospace Sciences Meeting, 2015, p. 1275.

[29] Morales, A. J., Geikie, M. K., Engelmann, C., and Ahmed, K., "Development and Characterization of a Turbulence Generator for Low-Speed Wind Tunnel Applications," 53rd AIAA/SAE/ASEE Joint Propulsion Conference, 2017, p. 4966.

[30] De Silva, I., and Fernando, H., "Oscillating grids as a source of nearly isotropic turbulence," Physics of Fluids, Vol. 6, No. 7, 1994, pp. 2455-2464.

[31] Marshall, A., Venkateswaran, P., Noble, D., Seitzman, J., and Lieuwen, T., "Development and characterization of a variable turbulence generation system,” Experiments in Fluids, Vol. 51, No. 3, 2011, p. 611.

[32] Jeong, Y. K., Jeon, C. H., and Chang, Y. J., "Evaluation of the equivalence ratio of the reacting mixture using intensity ratio of chemiluminescence in laminar partially premixed CH4-air flames," Experimental Thermal and Fluid Science, Vol. 30, No. 7 , 2006, pp. 663-673.

[33] JOHN, R. R., MARTIN SUMMERFIELD, “Effect of turbulence on radiation intensity from propane-air flames," Journal of Jet Propulsion, Vol. 27, No. 2, 1957, pp. 169-175.

[34] Chowdhury, B. R., and Cetegen, B. M., "Effects of free stream flow turbulence on blowoff characteristics of bluff-body stabilized premixed flames," Combustion and Flame, Vol. 190, 2018, pp. 302-316. 